\title{
How Shelterin Solves the Telomere End-Protection Problem
}

\author{
T. DE LANGE \\ Laboratory for Cell Biology and Genetics, The Rockefeller University, New York, New York 10065 \\ Correspondence: delange@rockefeller.edu
}

\begin{abstract}
The symphony of the human genome concludes with a long Gregorian chant of TTAGGG repeats. This monotonous coda represents one of the most complex problems in chromosome biology: the question of how cells distinguish their natural chromosome ends from double-strand breaks elsewhere in the genome. McClintock's classic finding of chromosome breakagefusion-bridge cycles, first reported by her at one of the early Cold Spring Harbor Laboratory Symposia (the ninth), served as a prelude to this question. The 75th Cold Spring Harbor Laboratory Symposium marks the completion of a series of mouse gene deletion experiments that revealed DNA-damage-response pathways that threaten chromosome ends and how the components of the telomeric shelterin complex prevent activation of these pathways.
\end{abstract}

\section{QUARTET OF THREATS}

In mammalian cells, four distinct pathways threaten chromosome ends: two DNA-damage signaling pathways, transduced by ATM (ataxia telangiectasia mutated) and ATR (ataxia telangiectasia and Rad3 re kinases, and two major double-strand break (DSB) repair pathways, nonhomologous end joining (NHEJ) and homology-directed repair (HDR) (Fig. 1). A short summary of the key aspects relevant to the telomere end-protection problem is given here. For primary references and more extensive details on these pathways, the reader is referred to excellent recent reviews on these subjects (Hefferin and Tomkinson 2005; Harper and Elledge 2007; Cimprich and Cortez 2008; Jackson and Bartek 2009; Mahaney et al. 2009; Mimitou and Symington 2009; Lieber 2010; Moynahan and Jasin 2010).

The ATM kinase pathway, particularly active in mammalian cells (more so than in yeast), is activated when the Mre11/Rad50/Nbs1 (MRN) complex associates with a DSB. This event helps to recruit the ATM kinase and mediates its activation in conjunction with the Tip60 acetyltransferase. The actual molecular mechanism of ATM activation is not understood. Once active, ATM can phosphorylate the histone variant $\mathrm{H} 2 \mathrm{AX}$, creating a large domain of phosphorylated $\mathrm{H} 2 \mathrm{AX}(\gamma-\mathrm{H} 2 \mathrm{AX})$ near the DSB. This chromatin modification functions to recruit MDC1 and a host of ubiquitin ligases that generate a cytologically defined entity referred to as a DNA-damage focus. Abundant residents of DNA-damage foci, such as 53BP1, $\gamma$ $\mathrm{H} 2 \mathrm{AX}, \mathrm{MRN}$, and MDC1, facilitate detection of the foci by indirect immunofluorescence. The formation of these foci is not required for ATM signaling but helps to amplify the signal, presumably through recruitment of additional ATM kinase molecules. In addition, some of the DNAdamage factors in the foci influence repair reactions. The outcomes of ATM signaling are mediated through the phosphorylation of numerous nucleoplasmic proteins that can affect events at a distance from the DSB. A key player is Chk2, which is activated by ATM-mediated phosphorylation and functions as an effector kinase, enforcing cell cycle arrest in $\mathrm{G}_{1} / \mathrm{S}$ and $\mathrm{G}_{2} / \mathrm{M}$ through phosphorylation of p53, MDM2, and Cdc25 phosphatases.

Activation of the ATR kinase pathway at DSBs requires lathe binding of replication protein A (RPA) to single-strand DNA (ssDNA). Resection of a DSB can create a $3^{\prime}$ overhang that, when decorated with RPA, binds the ATR-interacting protein (ATRIP) - binding partner of the ATR kinase. The activation of ATR signaling involves additional players, including TopBP1, the 9-1-1 complex, and its Rad17 clamp-loader. Once activated, ATR, like ATM, phosphorylates $\mathrm{H} 2 \mathrm{AX}$ in neighboring chromatin and DNA-damage foci are formed. Whether ATM- and ATRinduced foci are identical is not known, but so far, they have been indistinguishable in terms of their constituents. However, the DNA-damage foci have not been implicated in amplification of the ATR signal and may, therefore, be primarily important for the regulation of DNA repair. The ATR kinase has a large number of targets, including the effector kinase Chk1, which, when activated by ATR-mediated phosphorylation, induces cell cycle arrest in $\mathrm{G}_{1} / \mathrm{S}$ and $\mathrm{G}_{2} / \mathrm{M}$. Depending on the level of damage and the extent of repair, ATM or ATR signaling can lead to an irreversible arrest accompanied by either apoptosis or senescence.

NHEJ is an error-prone repair pathway that joins DSBs regardless of their sequence. This pathway is initiated by the Ku70/80 heterodimer, which binds DNA only when a free DNA end is available. The reason for this specificity emerged from structural analysis, which showed that the heterodimer is a ring-shaped protein with an opening the size of double-strand DNA. Once loaded, Ku70/80 mediates the synapsis of two DNA ends and facilitates their ligation by DNA ligase IV.

HDR is, in principle, error free, in particular when DSB repair takes place after DNA replication so that the sister chromatid can be used as a template. HDR requires end resection and loading of the Rad51 recombinase on a sin- 


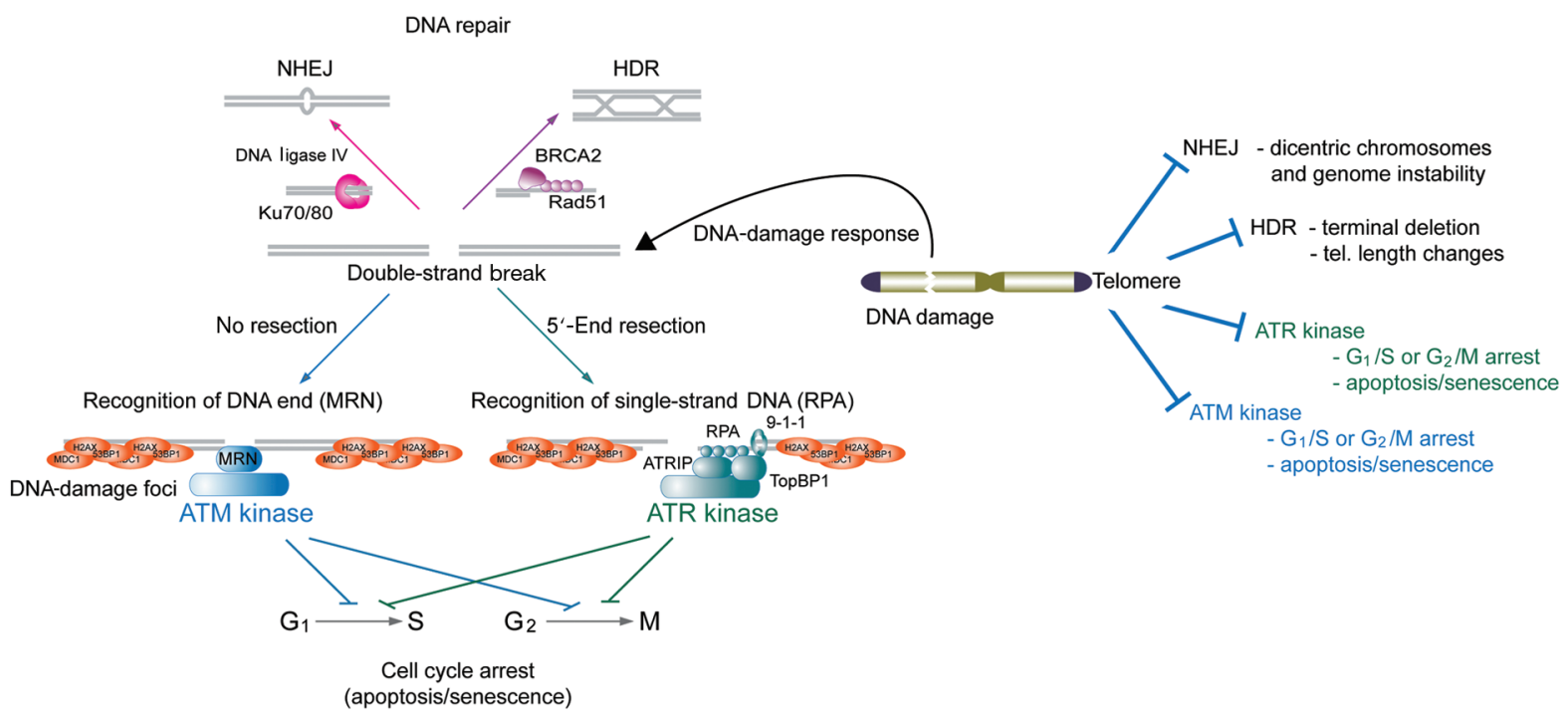

Figure 1. The end-protection problem in mammalian cells. Schematic shows the four pathways that threaten natural chromosome ends. At chromosome-internal DNA breaks, ATM and ATR signaling can be activated and the lesion can be repaired by NHEJ or HDR. Telomeres must repress all four pathways. Consequences of telomere dysfunction are indicated.

gle-strand 3' overhang. Rad51 mediates the invasion of the ssDNA into homologous sequences. After strand invasion, different further processing reactions can occur. If single or double Holliday junctions (HJs or dHJs) are formed, their resolution by resolvases Mus81/Eme1 or Gen1 can lead to sequence exchanges (crossovers), whereas their resolution by BLM/Top3a results in a noncrossover event. Additional outcomes of Rad51-mediated strand invasion include a single-strand annealing (SSA) pathway and break-induced replication (BIR).

These four pathways define the end-protection problem. Telomeres need to avoid activating the ATM and ATR kinase pathways because this would lead to cell cycle arrest. The "repair" of telomeres by NHEJ would generate lethal chromosome fusions, and HDR could change telomere length. Thus, in mammalian cells, telomeres need to block four distinct pathways that are each initiated in different ways.

\section{SHELTERIN: A SEXTET OF PROTECTIVE PROTEINS}

Mammalian telomeres are built up on long arrays of tandem TTAGGG repeats, the product of telomerase. The length of this repeat region is variable $(2-15 \mathrm{~kb}$ in humans, up to $100 \mathrm{~kb}$ in mice) and ends in a $3^{\prime}$ overhang of 50-400 nucleotides (Fig. 2). This DNA protects chromosome ends by recruiting shelterin.

Shelterin is a telomere-specific complex composed of six distinct subunits (Figs. 3 and 4). The complex derives its specificity for telomeric DNA from TRF1 and TRF2, two related homodimeric proteins that bind to doublestrand TTAGGG repeats with Myb/SANT-type DNA-binding domains (Chong et al. 1995; Bilaud et al. 1997; Broccoli et al. 1997). The complex contains a third DNAbinding protein, POT1, that has two oligosaccharide/ oligonucleotide binding $(\mathrm{OB})$ folds that associate with sin- gle-strand TTAGGG repeats (Baumann and Cech 2001; Loayza and de Lange 2003; Lei et al. 2004). The ssDNAbinding activity of POT1 is crucial for telomere protection but does not have a role in anchoring shelterin at telomeres (Loayza and de Lange 2003). POT1 is recruited to telomeres through its interaction with TPP1, another OB-foldcontaining protein (Liu et al. 2004; Ye et al. 2004b; Hockemeyer et al. 2007; Wang et al. 2007; Palm et al. 2009; Kibe et al. 2010). TPP1 binds to TIN2, which interacts with both TRF1 and TRF2 (Kim et al. 1999; Houghtaling et al. 2004; Liu et al. 2004; Ye et al. 2004a,b; O'Connor et al. 2006; Chen et al. 2008). The telomere binding of POT1 is critically dependent on this TPP1/TIN2 link to the proteins that anchor shelterin on double-strand

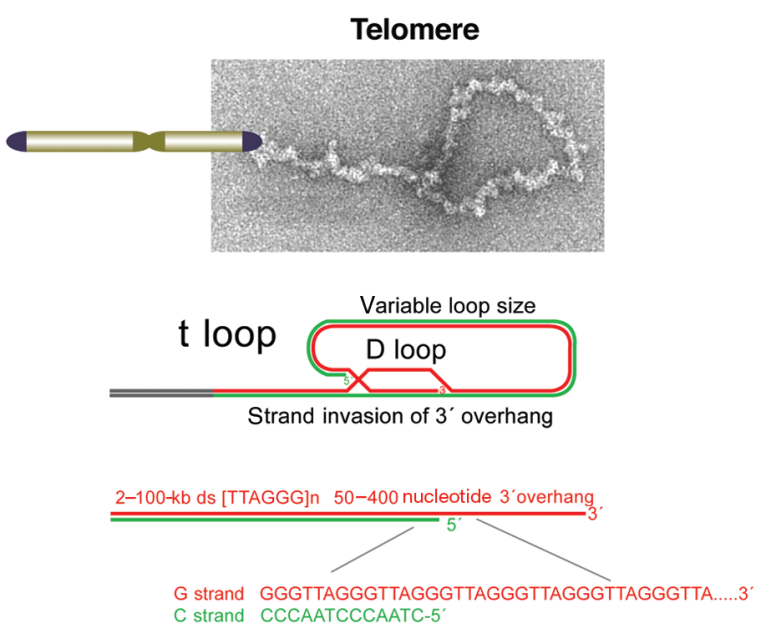

Figure 2. Structure of mammalian telomeres and schematic of the DNA component of mammalian telomeres. Micrograph shows a t-loop in isolated chromatin. (Reprinted, with permission, from Nikitina and Woodcock 2004 [CRockefeller University Press].) 


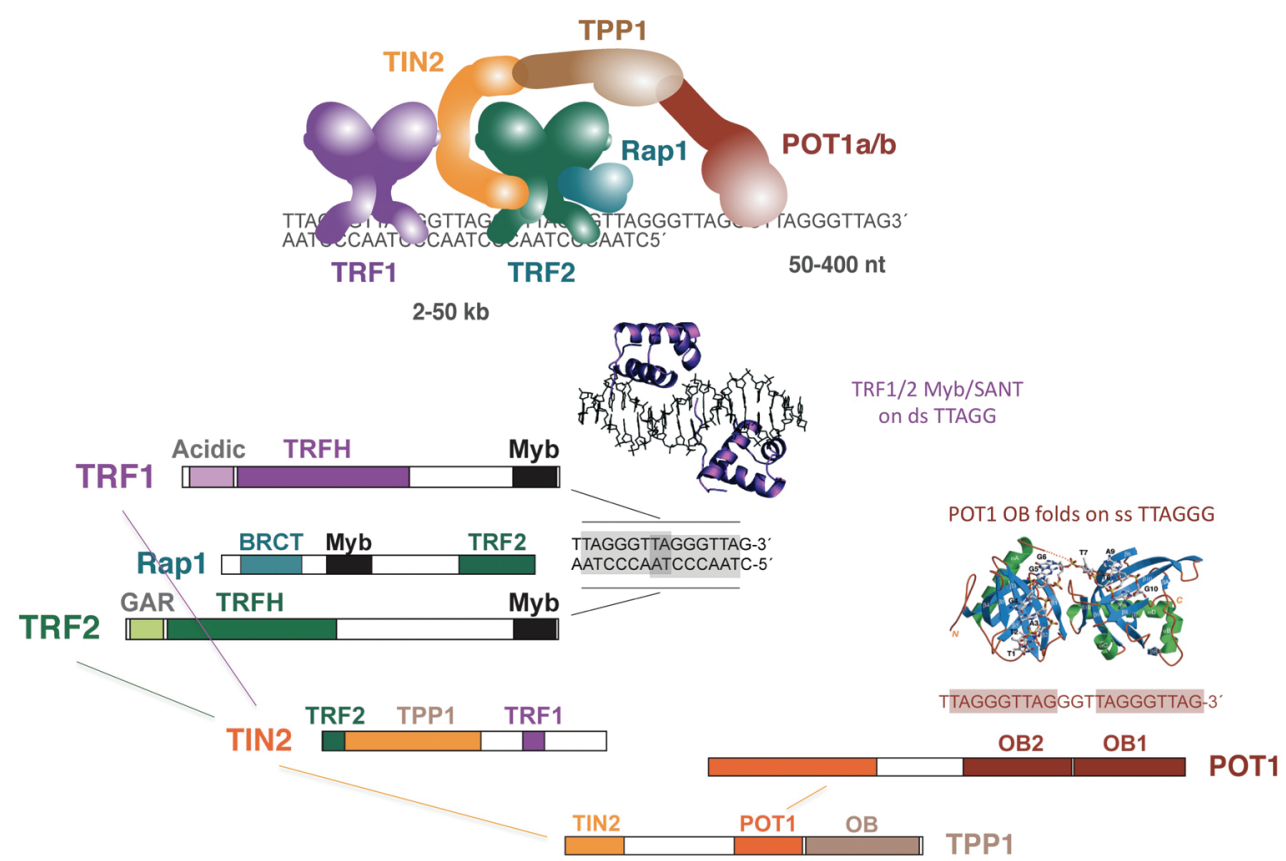

Figure 3. Components of human shelterin, their domain structure, and their interactions with telomeric DNA. (The structure of the Myb domain is from Rhodes 2005 [CCold Spring Harbor Laboratory Press]; the structure of the human POT1 domain is from Lei et al. 2004 [@Nature Publishing Group].)

TTAGGG repeats. A sixth subunit in the complex, a distant ortholog of the yeast Rap1, was discovered as a TRF2binding protein (Li et al. 2000). Whereas TRF1, TRF2, TIN2, TPP1, and POT1 are dedicated to telomeres, Rap1 was recently shown to also have a role in transcriptional regulation (Martinez et al. 2010; Teo et al. 2010).

The TRF1/TRF2/TIN2/Rap1 core of shelterin is very abundant (Fig. 4). Estimates suggest that human telomeres could contain hundreds of copies of this complex, potentially covering all telomeric DNA (Takai et al. 2010). Although POT1 and TPP1 are less abundant ( $\sim 50$ copies per telomere), POT1 is likely to be present in excess of its single-strand binding sites. In addition to shelterin, telomeric DNA is associated with nucleosomes (Makarov et al. 1993; Tommerup et al. 1994; Lejnine et al. 1995; Nikitina and Woodcock 2004; Wu and de Lange 2008). The details of how shelterin binds to nucleosomal chromatin are beginning to be addressed (Galati et al. 2006; Baker et al. 2009). It should also be noted that shelterin components,
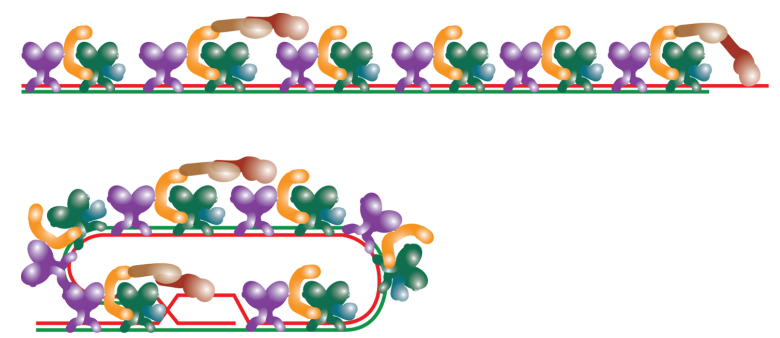

Figure 4. Shelterin on telomeric DNA. Relative abundance of the shelterin components and how they might be bound to telomeres in the t-loop configuration. in particular TRF1 and TRF2, can be modified in numerous ways (parsylation, ubiquitylation, sumoylation, phosphorylation, Arg methylation, and prolyl isomerization) and the functional consequences of these modifications are being explored (Smith et al. 1998; Lee et al. 2006, 2009; Potts and Yu 2007; Kim et al. 2008; Wu et al. 2008; Atanassov et al. 2009; Chen et al. 2009; Her and Chung 2009; Zeng et al. 2010).

Shelterin is highly conserved in mammals, including mice. Because of this conservation, it has been possible to determine the function of each of the shelterin subunits using gene targeting in the mouse. The only distinction in rodents is the presence of a second POT1 protein (Hockemeyer et al. 2006). The two rodent POT1 proteins POT1a/b are the result of a recent gene duplication event. Both POT1a and POT1b interact with TPP1, and both are approximately equally abundant at telomeres, but they have distinct functions, as discussed below.

\section{A SUITE OF SHELTERIN ACCESSORY PROTEINS}

Shelterin recruits numerous accessory proteins to telomeres. These proteins are not telomere specific, often having prominent roles in general genome maintenance. Examples are MRN (Zhu et al. 2000), Ku70/80 (Hsu et al. 2000; O'Connor et al. 2004), ERCC1/XPF (Zhu et al. 2003), WRN and BLM RecQ helicases (Opresko et al. 2002), PARP1/2 (Dantzer et al. 2004; Gomez et al. 2006), FEN-1 (Muftuoglu et al. 2006; Saharia et al. 2008; Saharia and Stewart 2009), SLX4 (Svendsen et al. 2009), and Mus81 (Zeng et al. 2009). For most of these factors, it is 
known (or suspected) that they interact with shelterin, but the molecular details are largely unknown. A well-studied shelterin accessory factor is the Apollo SMN1/Pso2-type nuclease (also referred to as SNM1B), which has a general function in DNA interstrand-cross-link repair. Apollo binds to TRF2 and contributes to the maintenance of the G-strand overhang and the protection of telomeres in S phase (Freibaum and Counter 2006; Lenain et al. 2006; van Overbeek and de Lange 2006; Chen et al. 2008; Lam et al. 2010; Wu et al. 2010).

Unlike most shelterin accessory factors, which are nuclear proteins, the tankyrase class of PARPs (Smith et al. 1998; Kaminker et al. 2001), which were the first shelterin accessory factors to be discovered, are now known to have a variety of functions in the cytoplasm (for review, see Hsiao and Smith 2008). However, tankyrases also bind to TRF1 and contribute to telomere length regulation and telomere resolution in mitosis (Smith and de Lange 2000; Dynek and Smith 2004). Interestingly, the tankyrase-TRF1 interaction is not conserved in mouse cells (Donigian and de Lange 2007), providing another example of the slight differences between mouse and human telomeres.

\section{MUTING ATM AND ATR}

Activation of either the ATM or ATR kinase pathway by the natural ends of chromosomes is incompatible with cellular and organismal survival. Both pathways are kept in check by shelterin. There is a remarkable division of labor within the complex, with TRF2 dedicated to the ATM pathway and POT1 responsible for the repression of ATR (Figs. 5-7) (Lazzerini Denchi and de Lange 2007).
When TRF2 is deleted from mouse embryonic fibroblasts (MEFs), most (if not all) telomeres become sites of ATM activation (Celli and de Lange 2005). The MRN complex accumulates locally, and ATM signaling phosphorylates $\mathrm{H} 2 \mathrm{AX}$ in telomeric and subtelomeric chromatin, resulting in accumulation of other DNA-damage-response factors, including MDC1 and 53BP1 at/near telomeres. Cytologically, these events are readily detectable as the occurrence of numerous DNA-damage foci that colocalize with telomeric markers (referred to as telomere dysfunction-induced foci [TIFs]; Takai et al. 2003). The TIF assay helps to evaluate the level of telomere deprotection in a quantitative manner. When ATM or components of the MRN complex are genetically inactivated in MEFs, the deletion of TRF2 fails to induce the TIF response (Celli and de Lange 2005; Attwooll et al. 2009; Deng et al. 2009; Dimitrova and de Lange 2009). This provides formal proof that TRF2 is required for the repression of ATM but not ATR signaling. Consistent with the activation of the ATM pathway following loss of TRF2, Chk2 is activated, and upregulation of $\mathrm{p} 53$ results in induction of $\mathrm{p} 21$, and consequently, $\mathrm{G}_{1} / \mathrm{S}$ arrest (Karlseder et al. 1999). To avoid the confounding aspects of working with arrested cell populations, most shelterin deletion experiments are executed in a p53-null setting (either through genetic ablation or by immortalizing the MEFs with SV40 large T).

Work with a temperature-sensitive allele of TRF2 showed that loss of TRF2 from telomeres activates the ATM pathway in all stages of the cell cycle and that the activation is quick ( $<4 \mathrm{~h})$ (Konishi and de Lange 2008). Furthermore, these experiments showed that the DNAdamage signal emanating from the deprotected telomeres
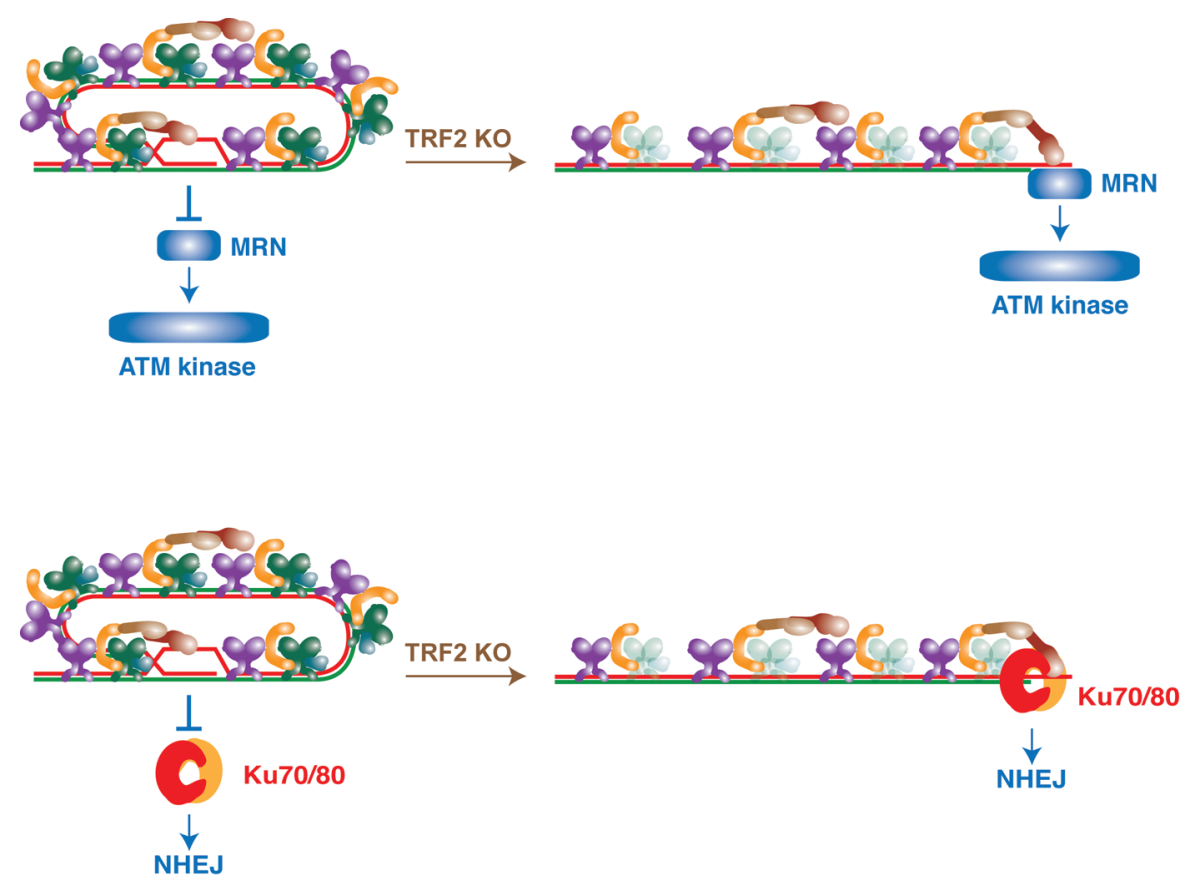

Figure 5. Model for repression of ATM signaling and NHEJ by TRF2. TRF2 is proposed to maintain the t-loop structure. When telomeres are in the t-loop configuration, neither the MRN complex (top) nor the Ku70/80 complex can gain access to the telomere terminus, thereby preventing the initiation of ATM signaling and NHEJ. 

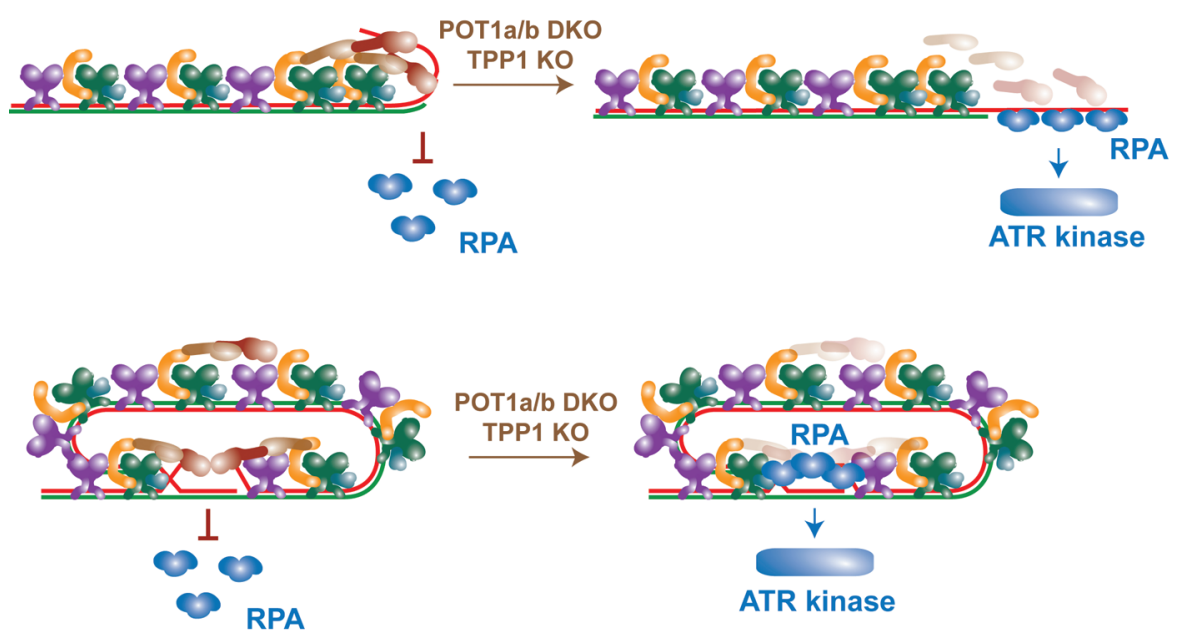

Figure 6. Model for repression of ATR signaling by POT1a/b. POT1a/b are proposed to repress ATR signaling by excluding RPA from the single-strand telomeric DNA. This model pertains to telomeres in a linear and $t$-loop state. POT1a/b require the tethering to TPP1TIN2-TRF1/2 for it to compete effectively with RPA.

can be readily reversed. When cells are moved back to the permissive temperature, the TIF response dissipates in a few hours. The ability of TRF2 to establish and maintain a telomere state that hides the chromosome end from the ATM pathway does not require its interacting factor Rap1 (Sfeir et al. 2010). The role of the second TRF2-binding protein in shelterin, TIN2, in the repression of ATM has not been established. The TRF2-binding protein Apollo has a minor contribution in the muting of ATM (Wu et al. 2010). Deletion of Apollo results in ATM-dependent TIFs, but they occur only in $\mathrm{S}$ phase.

Assuming that TRF2 is the main player in blocking the activation of the ATM kinase, the question arises as to how a simple DNA-binding factor such as TRF2 accomplishes this task. The current model invokes a key role for TRF2 in the formation of the t-loop structure (Fig. 5). t-loops are lariats formed by the strand invasion of the $3^{\prime}$ telomeric overhang into the duplex telomeric DNA (Fig. 2). They were initially observed by electron microscopy (EM) analysis of telomeric DNA isolated from psoralen crosslinked nuclei of human and mouse cells (Griffith et al. 1998). The strand invasion displaces the G-rich telomeric strand at the base of the loop, forming a D loop that was inferred to be present based on coating with an Escherichia coli single-stranded DNA-binding protein. t-loops are a conserved aspect of telomeres; they have been detected in trypanosomes (Munoz-Jordan et al. 2001), ciliate micronuclear DNA (Murti and Prescott 1999), plants (Cesare et al. 2003), and some strains of Kluyveromyces lactis (Cesare et al. 2008). t-loops have also been demonstrated in isolated intact chromatin from chicken erythrocytes and mouse splenocytes (Nikitina and Woodcock 2004). Furthermore, TRF2 has biochemical activities in vitro that suggest a role in t-loop formation. Recombinant TRF2 can generate t-loops when provided with an appropriate telomeric substrate (Griffith et al. 1999; Stansel et al. 2001),

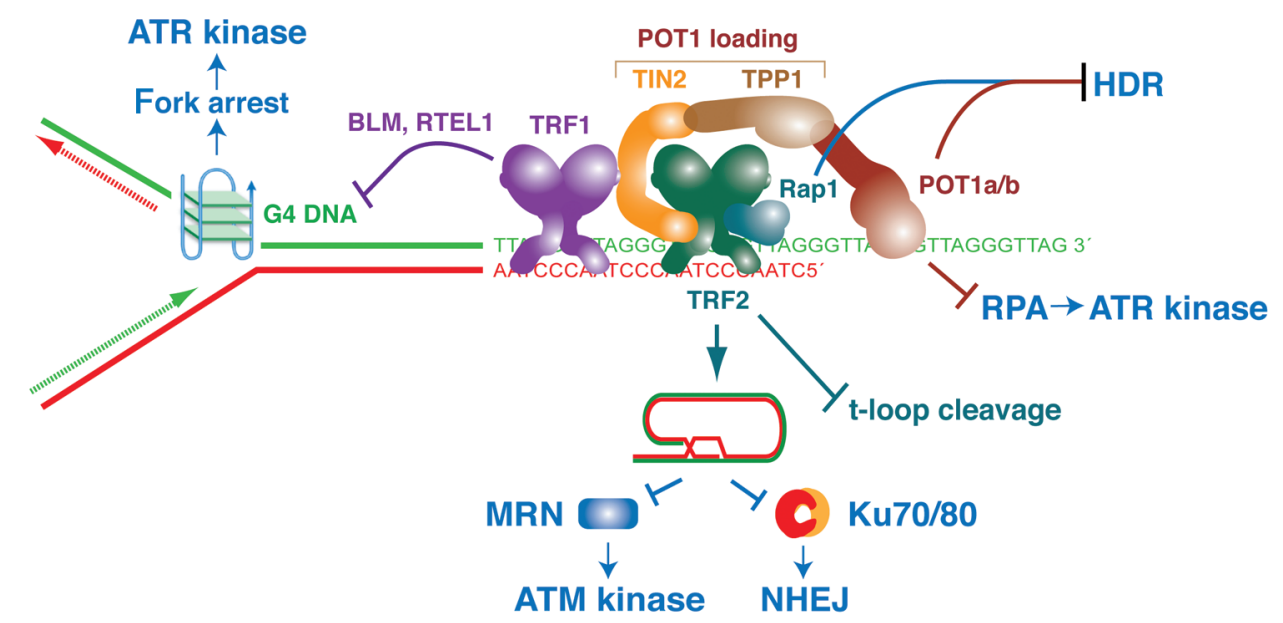

Figure 7. The way in which shelterin solves the end-protection problem. Overview of the functions assigned to each shelterin component. See text for details. 
and it can bind to HJs (Fouche et al. 2006; Amiard et al. 2007; Poulet et al. 2009), suggesting that it could stabilize the strand-invasion point. Whether TRF2 is indeed required for the maintenance of t-loops in vivo remains to be determined. The way in which t-loops are thought to block ATM kinase signaling is by simple end occlusion. The strand invasion of the $3^{\prime}$ overhang generates an altered state for the telomere end that is expected to block any DNA-binding complex that loads onto DNA ends. Thus, t-loops would safeguard the telomeres against the loading of MRN, thereby preventing ATM kinase activation.

The ATR kinase pathway is within the jurisdiction of the ssDNA-binding activity of POT1 (Figs. 6 and 7). Deletion of POT $1 \mathrm{a} / \mathrm{b}$ from MEFs results in TIF formation at most telomeres, and this response is abrogated when ATR is inhibited (Hockemeyer et al. 2006; Lazzerini Denchi and de Lange 2007). Removal of the ATM kinase has no effect on the TIF response in POT1-deficient cells (Lazzerini Denchi and de Lange 2007). POT1-deficient cells show phosphorylation of Chk1 (and Chk2), and this downstream readout for ATR signaling is curbed by ATR inhibition. In mouse cells, POT1a is the primary factor in the repression of ATR, with POT1b having a subsidiary role (Hockemeyer et al. 2006). POT1b has a distinct function at mouse telomeres in regulating the length of the $3^{\prime}$ telomeric overhang (Hockemeyer et al. 2006, 2008). Work with chimeric proteins showed that the difference between POT1a/b resides in their DNA-binding domains (Palm et al. 2009), pointing to the ssDNA-binding features of these proteins as crucial for ATR repression. Because the ATR pathway is activated following binding of RPA to ssDNA, a simple RPA exclusion model has been proposed (Guo et al. 2007; Lazzerini Denchi and de Lange 2007; Churikov and Price 2008). According to this model, the presence of POT1 on the single-strand telomeric DNA (either the $3^{\prime}$ overhang when the telomere is in an open state or the D loop in the t-loop configuration) would block RPA from binding and thereby prevent the activation of the ATR signaling pathway (de Lange 2009). Consistent with this model, RPA is detectable at telomeres when POT $1 \mathrm{a} / \mathrm{b}$ are removed, and RPA is indeed required for the activation of the ATR pathway at telomeres lacking POT1 protection (Gong and de Lange 2010). However, a complication has arisen from the analysis of the DNA-binding features of POT1 and RPA. The affinity of POT1a (or human POT1) for single-strand telomeric DNA is in the same range as the RPA-binding affinity, even when POT1a is present as a heterodimer with TPP1 (T Kibe and T de Lange, in prep.). Furthermore, the POT1 proteins in human and mouse cells are 10- to 100-fold less abundant than RPA (T Kibe and T de Lange, in prep.).

Despite its low abundance and comparable Kd (dissociation constant) for single-strand TTAGGG repeats, POT1a/b exclude RPA from single-strand telomeric DNA. Most likely, POT1 is effective in the competition with RPA because it is tethered to the other shelterin components. Through its TPP1-TIN2 link, POT1 accumulates at telomeres and this connection provides POT1 with two telomeric-binding sites (one through protein-protein interaction and the second representing the POT1-DNA interaction) rather than the single DNA interaction avail- able to RPA. Therefore, it is expected that the actual $\mathrm{Kd}$ of POT1 for the single-strand telomeric DNA in vivo is much lower than that for RPA. When POT1 releases the singlestrand telomeric DNA, its on-rate will be much higher than for an RPA molecule that has lost its grip on TTAGGG repeats. Experimental evidence in favor of this view comes from the TPP1 knockout (KO), which recapitulates the POT1a/b double-KO (DKO) phenotype (Kibe et al. 2010). Further in vitro and in vivo tests for this tethering model are needed to address this issue in detail.

ATR signaling is also activated when TRF1 is deleted, although POT1a/b remain associated with telomeres (Fig. 7) (Sfeir et al. 2009). In the TRF1-deleted cells, ATR activation is dependent on progression through $\mathrm{S}$ phase (Sfeir et al. 2009), which is not the case when POT1a/b are removed (Gong and de Lange 2010). The origin of the ATR signal in telomere replication is a problem that arises when TRF1 is not present. Replication of telomeric DNA is twofold less efficient when TRF1 is deleted but is not affected by loss of TRF2 (Sfeir et al. 2009). The current model is that telomeric replication falters when G4 structures are encountered, and TRF1 may remove these barriers by recruiting BLM and RTEL helicases (Sfeir et al. 2009). When TRF1 is not present, this replication defect ultimately leads to a fragile-site-like phenotype at telomeres (Martinez et al. 2009; Sfeir et al. 2009). Thus, the TRF1 component of shelterin has a dual role at telomeres. Like TRF2, it ensures the presence of POT1 at telomeres, but in addition, it has an S-phase-specific role in promoting the replication of telomeric DNA.

\section{PAUSING NHEJ}

NHEJ at telomeres needs to be tightly repressed. Even a single telomere-telomere fusion can kill cells by forming a dicentric chromosome that blocks mitosis, mis-segregates, or breaks in mitosis and generates a DSB that can wreck the genome. NHEJ is primarily blocked by TRF2 (van Steensel et al. 1998; Smogorzewska et al. 2002; Celli and de Lange 2005). Inhibition of TRF2 generates numerous chromosome end fusions, ultimately resulting in long strings of joined chromosomes (Celli and de Lange 2005). Work with the TRF2 ts allele has shown that NHEJ takes place primarily in $\mathrm{G}_{1}$, but postreplicative fusions are also observed (Konishi and de Lange 2008). As with activation of the ATM kinase, telomere fusions can be induced with a short period of TRF2 inactivation, indicating that TRF2 constantly maintains a telomere state that resists this repair reaction. Moreover, as with the repression of ATM kinase signaling, TRF2 appears to do the job largely alone because deletion of Rap1 does not lead to telomere fusions (Martinez et al. 2010; Sfeir et al. 2010). Therefore, the current model is similar to the t-loop model for ATM kinase repression. The t-loop structure is expected to block the Ku70/80 complex from loading on the telomere end, thereby preventing NHEJ at its very first step (Fig. 5).

The TRF2-mediated repression of telomere fusions is sufficient to protect chromosome ends in $\mathrm{G}_{1}$, but after DNA replication, additional mechanisms are needed. This is clear from the mild telomere fusion phenotype of the POT1a/b DKO (Fig. 7) (Hockemeyer et al. 2006). Inter- 
estingly, these fusions primarily involve sister chromatids, indicating a postreplicative event. Thus, after DNA replication, both sister telomeres (one formed by laggingstrand DNA synthesis and one by leading-strand DNA synthesis) become vulnerable to a joining event, although the incidence of actual fusions is low. Perhaps the loading of POT1 on the single-strand overhang keeps the repair pathway at bay until the t-loop structure is reformed. Consistent with this view, leading-end telomeres (which are presumably blunt right after DNA replication is completed) require the Apollo nuclease for their proper protection from fusion (Lam et al. 2010; Wu et al. 2010). Apollo has been implicated in the regeneration of the 3' overhang at telomeres after their replication (Lam et al. 2010; Wu et al. 2010). A simple scenario can be envisaged in which TRF2 recruits Apollo to regenerate the 3' overhang at leading-end telomeres, which then become covered by POT1 so that joining reactions are blocked in the period before the t-loop is reformed. The lagging-end telomere is thought to contain an overhang that is generated by removal of the last RNA primer so that resection may not be needed immediately. In contrast, POT1 binding would be needed at both ends, explaining why Apollo $\mathrm{KO}$ cells have leading-end fusions, whereas POT1a/b DKO cells show fusions of sister telomeres.

Apollo is probably not the only nuclease that mediates the generation of the $3^{\prime}$ overhang at leading-end telomeres. When Apollo is absent, the leading-end telomere fusions occur but are not frequent, suggesting that there is another pathway that can generate a $3^{\prime}$ overhang when Apollo is missing. One possibility is that the ATM signaling at telomeres lacking Apollo is responsible for the resection. MRN-mediated ATM activation can induce resection at DSBs, most likely through the CtIP nuclease. Indication that the MRN/ATM-dependent resection can protect leading-end telomeres from NHEJ came from experiments in which TRF2 is deleted from MRN- or ATM-deficient cells (Attwooll et al. 2009; Dimitrova and de Lange 2009). Because TRF2 is able to recruit MRN to telomeres, it is also possible that the MRN/ATM/CtIP pathway acts in parallel with Apollo to generate a $3^{\prime}$ overhang at the leading-end telomeres. It will therefore be interesting to monitor the leading-end telomere fusions in Apollo/MRN or Apollo/ ATM double-deficient cells.

It should be noted that postreplicative telomere fusions are not necessarily mediated by NHEJ. Deficiency in DNA ligase IV does not abrogate the postreplicative telomere fusions occurring when either POT1a/b (Rai et al. 2010) or Apollo (P Wu and T de Lange, unpubl.) is removed. This may point to the recently described mammalian alternative end joining pathway, but genetic evidence in favor of this view is not yet available. Therefore, it is not excluded that the observed "fusions" are, in fact, noncovalent associations.

\section{DIRECTING HDR}

Compared to the acutely lethal outcomes of NHEJ, HDR may seem less threatening to telomeres. Yet, inappropriate recombination between telomeres can have dire consequences in the long term. For instance, if two sister telomeres undergo an unequal exchange, one of the daughter cells will inherit a shortened telomere. In human somatic cells without telomerase, this shortened telomere will likely limit the life span of the lineage established by the dispossessed daughter. In addition, BIR could inappropriately extend telomeres and has been invoked as the primary mechanism by which some telomerase negative cell lines and tumors extend their telomeres. This so-called alternative lengthening of telomeres (ALT) pathway is thought to involve BIR-like telomere extension events using either telomeres or extrachromosomal telomeric DNA as a template (Dunham et al. 2000).

HDR can be monitored at telomeres using chromosome-orientation fluorescence in situ hybridization (CO-FISH), which labels the telomeres generated by leading- and lagging-strand synthesis with two different fluorophores so that sequence exchanges between sister telo-meres can be visualized. These telomere sister chromatid exchanges (T-SCEs) are rare in wild-type cells (one or two per metaphase spread) but can become prominent when TRF2 is deleted (Celli et al. 2006). Induction of TSCEs by loss of TRF2 is only detectable in Ku70/80-deficient cells. When Ku70/80 is present, even when NHEJ is blocked by the absence of DNA ligase IV, exchanges are rare (Celli et al. 2006). How Ku70/80 acts to prevent T-SCEs has not been established, but it may be related to the general ability of Ku70/80 to repress HDR. Alternatively, the association of Ku70/80 with shelterin may be important for the repression of HDR.

Although T-SCEs are frequent in cells lacking TRF2 (and $\mathrm{Ku} 70 / 80$ ), TRF2 itself is not involved in regulating this reaction. Rather, Rap1 is repressing HDR. As with the TRF2 phenotype, Rap1 KO cells show a minimal level of T-SCEs ( $<2 \%$ ) (Martinez et al. 2010; Sfeir et al. 2010), but in a Ku70-null context, the T-SCEs are very frequent $(\sim 10 \%$ of chromosome ends) (Sfeir et al. 2010). How Rap1 protects telomeres from HDR is unclear. Rap1 is a small adapter protein with several domains that could bind other factors, so perhaps it has an interacting partner that blocks HDR. The view of Rap1 as an adapter can also explain its varied roles at telomeres in other organisms and the recently established role for Rap1 in NF- $\mathrm{KB}$ signaling (Teo et al. 2010).

In addition to Rap1, POT1 proteins in shelterin are required for the repression of HDR. POT1a/b-Ku70 triple$\mathrm{KO}$ cells show the same high frequency of T-SCEs as the TRF2 or Rap1/Ku70 DKO cells (Palm et al. 2009). Either POT 1a or b is sufficient to repress this phenotype. As with the Rap1 KO, low levels of T-SCEs have been reported in POT1a- or b-deficient cells, but it is difficult to evaluate these minor phenotypes (He et al. 2006; Wu et al. 2006). Thus, the repression of recombination between telomeres by shelterin involves the concerted action of one of the two POT1 proteins and Rap1.

Shelterin is also required to prevent an HDR reaction that cleaves the t-loop off the telomere. This reaction produces a shortened telomere and an extrachromosomal circular DNA composed of telomeric repeats (referred to as a t circle) that is detectable on two-dimensional gels (Wang et al. 2004). The simplest explanation of these products is the formation (through branch migration) of a $\mathrm{dHJ}$ at the base of 
the t-loop and a crossover-type resolution by Mus81 or Gen1 (Haber 2004). t-loop cleavage is specifically repressed by the amino-terminal domain of TRF2, which is rich in Gly/Arg residues and highly basic (referred to as the basic domain or the Gly/Arg-rich [GAR] domain). The GAR domain is a signature of mammalian TRF2; it is absent from mammalian TRF1, chicken and Xenopus TRF2, and the TRF-related Taz1p of fission yeast. Recent biochemical data have suggested that the GAR domain binds to HJs (Fouche et al. 2006; Amiard et al. 2007; Poulet et al. 2009). It has therefore been proposed that the amino terminus of TRF 2 prevents t-loop cleavage by physically blocking resolvases from gaining access to $\mathrm{dHJ}$ that might be formed at the base of the t-loop.

\section{ENCORE: TELOMERES AS A TOOL TO STUDY THE DNA-DAMAGE RESPONSE}

Different shelterin subunits repress different branches of the DNA-damage response. The corollary of this compartmentalization is that deletion of individual shelterin proteins can be used to activate a specific DNA-damage-response pathway without others becoming involved. The ATM kinase pathway can be activated without any signaling by ATR or HDR/NHEJ by removing TRF2 from telomeres of cells that lack DNA ligase IV. In contrast, ATR signaling can be specifically activated in the absence of ATM signaling in POT1a/b DKO cells. Deletion of Rap1 from Ku70deficient cells generates the unique situation of ongoing HDR at telomeres without NHEJ, ATM signaling, or ATR signaling. These surgical alterations can be explored to gain insights into the DNA-damage response that are not readily obtained from the more popular methods of induction of DNA damage (e.g., ionizing radiation, ultraviolet [UV], and site-specific cleavage with ISceI, and V(D)J [variable, diverse, and joining] recombination).

Several insights have already emerged from studying telomere dysfunction. The rampant NHEJ at telomeres typical of TRF2-deficient cells is largely abrogated when the ATM kinase is not present (Lazzerini Denchi and de Lange 2007; Dimitrova and de Lange 2009). It is the signaling by the ATM kinase that is critical for efficient NHEJ. The key target of ATM in this setting is 53BP1. Removal of TRF2 from telomeres in 53BP1-deficient cells results in hardly any NHEJ events, although ATM kinase signaling is not disrupted (Dimitrova et al. 2008). This result was not anticipated because $53 \mathrm{BP} 1$ had not been identified as a player needed for NHEJ in the context of most V(D)J recombination or general DSB repair. The only other settings where 53BP1 is required for NHEJ are in class switch recombination (CSR) (Reina-San-Martin et al. 2007) and V(D)J recombination between distant sites (Difilippantonio et al. 2008). CSR, long-range V(D)J, and telomere fusions all have DNA ends that are far apart. It is therefore possible that 53BP1 functions in mediating synapsis. Studies of deprotected telomeres have suggested a second (not mutually exclusive) possibility. 53BP1 was found to greatly stimulate the mobility of deprotected telomeres in the nucleus, presumably increasing their chance of encountering a fusion partner (Dimitrova et al. 2008).
Another new insight into the consequences of the DNAdamage response was obtained with the POT1a/b DKO cells (Davoli et al. 2010). ATR signaling in the POT1a/b DKO cells is unusual compared to most settings in which ATR is activated (e.g., UV) in that the "damage" is irreparable. The origin of ATR activation is single-strand telomeric DNA, and this "lesion" can only be repaired by an NHEJ reaction that joins to two telomeres and cleaves the overhang in the process. However, in POT1a/b DKO cells, telomere joining is rare, most likely because NHEJ continues to be inhibited by TRF2, which remains on the telomeres (Hockemeyer et al. 2006). As a consequence, ATR signaling persists for days if not weeks. Detailed analysis of the cell cycle and DNA replication behavior of POT1a/b DKO cells showed that such persistent DNAdamage signaling induces endoreduplication. The cells, which do not arrest in $\mathrm{G}_{1} / \mathrm{S}$ due to the absence of $\mathrm{p} 53$, display a long $\mathrm{G}_{2}$ phase but ultimately bypass mitosis and reenter a second $\mathrm{S}$ phase, thereby generating tetraploid cells (Davoli et al. 2010).

This telomere-driven tetraploidization could be relevant to the development of aneuploidy in human cancer. Telomere dysfunction is likely to occur during the development of a substantial fraction of human cancers. If the telomere damage is not readily resolved and occurs in a $\mathrm{p} 53 / \mathrm{Rb}$-deficient setting, tetraploid cells are predicted to arise. Tetraploid cells have been observed in the early stages of human tumorigenesis and are proposed to constitute a likely precursor for the genesis of aneuploidy (Storchova and Pellman 2004).

\section{ACKNOWLEDGMENTS}

Work in my laboratory is done under the auspices of grants from the National Institutes of Health (OD000379, GM049046, AG016642, CA076027) and with support of the Breast Cancer Research Foundation and the Starr Foundation. I am a Professor of the American Cancer Society.

\section{REFERENCES}

Amiard S, Doudeau M, Pinte S, Poulet A, Lenain C, FaivreMoskalenko C, Angelov D, Hug N, Vindigni A, Bouvet P, et al. 2007. A topological mechanism for TRF2-enhanced strand invasion. Nat Struct Mol Biol 14: 147-154.

Atanassov BS, Evrard YA, Multani AS, Zhang Z, Tora L, Devys D, Chang S, Dent SYR. 2009. Gcn5 and SAGA regulate shelterin protein turnover and telomere maintenance. Mol Cell 35: 352-364.

Attwooll CL, Akpinar M, Petrini JH. 2009. The Mre11 complex and the response to dysfunctional telomeres. Mol Cell Biol 29: $5540-5551$.

Baker AM, Fu Q, Hayward W, Lindsay SM, Fletcher TM. 2009. The Myb/SANT domain of the telomere-binding protein TRF2 alters chromatin structure. Nucleic Acids Res 37: 5019-5031.

Baumann P, Cech TR. 2001. Pot1, the putative telomere end-binding protein in fission yeast and humans. Science 292: 11711175.

Bilaud T, Brun C, Ancelin K, Koering CE, Laroche T, Gilson E. 1997. Telomeric localization of TRF2, a novel human telobox protein. Nat Genet 17: 236-239.

Broccoli D, Smogorzewska A, Chong L, de Lange T. 1997. Human telomeres contain two distinct Myb-related proteins, TRF1 and TRF2. Nat Genet 17: 231-235. 
Celli G, de Lange T. 2005. DNA processing not required for ATMmediated telomere damage response after TRF2 deletion. Nat Cell Biol 7: 712-718.

Celli GB, Lazzerini Denchi E, de Lange T. 2006. Ku70 stimulates fusion of dysfunctional telomeres yet protects chromosome ends from homologous recombination. Nat Cell Biol 8: 885-890.

Cesare AJ, Quinney N, Willcox S, Subramanian D, Griffith JD. 2003. Telomere looping in $P$. sativum (common garden pea). Plant J 36: 271-279.

Cesare AJ, Groff-Vindman C, Compton SA, McEachern MJ, Griffith JD. 2008. Telomere loops and homologous recombinationdependent telomeric circles in a Kluyveromyces lactis telomere mutant strain. Mol Cell Biol 28: 20-29.

Chen Y, Yang Y, van Overbeek M, Donigian JR, Baciu P, de Lange T, Lei M. 2008. A shared docking motif in TRF1 and TRF2 used for differential recruitment of telomeric proteins. Science 319: 1092-1096.

Chen YC, Teng SC, Wu KJ. 2009. Phosphorylation of telomeric repeat binding factor 1 (TRF1) by Akt causes telomere shortening. Cancer Invest 27: 24-28.

Chong L, van Steensel B, Broccoli D, Erdjument-Bromage H, Hanish J, Tempst P, de Lange T. 1995. A human telomeric protein. Science 270: 1663-1667.

Churikov D, Price CM. 2008. Pot1 and cell cycle progression cooperate in telomere length regulation. Nat Struct Mol Biol 15: 79-84.

Cimprich KA, Cortez D. 2008. ATR: An essential regulator of genome integrity. Nat Rev Mol Cell Biol 9: 616-627.

Dantzer F, Giraud-Panis MJ, Jaco I, Ame JC, Schultz I, Blasco M, Koering CE, Gilson E, Menissier-de Murcia J, de Murcia G, et al. 2004. Functional interaction between poly(ADP-ribose) polymerase 2 (PARP-2) and TRF2: PARP activity negatively regulates TRF2. Mol Cell Biol 24: 1595-1607.

Davoli T, Denchi EL, de Lange T. 2010. Persistent telomere damage induces bypass of mitosis and tetraploidy. Cell 141: 81-93.

de Lange T. 2009. How telomeres solve the end-protection problem. Science 326: 948-952.

Deng Y, Guo X, Ferguson DO, Chang S. 2009. Multiple roles for MRE11 at uncapped telomeres. Nature 460: 914-918.

Difilippantonio S, Gapud E, Wong N, Huang CY, Mahowald G, Chen HT, Kruhlak MJ, Callen E, Livak F, Nussenzweig MC, et al. 2008. 53BP1 facilitates long-range DNA end-joining during V(D)J recombination. Nature 456: 529-533.

Dimitrova N, de Lange T. 2009. Cell cycle-dependent role of MRN at dysfunctional telomeres: ATM signaling-dependent induction of nonhomologous end joining (NHEJ) in $\mathrm{G}_{1}$ and resection-mediated inhibition of NHEJ in $\mathrm{G}_{2}$. Mol Cell Biol 29: 5552-5563.

Dimitrova N, Chen YC, Spector DL, de Lange T. 2008. 53BP1 promotes non-homologous end joining of telomeres by increasing chromatin mobility. Nature 456: 524-528.

Donigian JR, de Lange T. 2007. The role of the poly(ADP-ribose) polymerase tankyrase 1 in telomere length control by the TRF1 component of the shelterin complex. J Biol Chem 282: 22662 22667.

Dunham MA, Neumann AA, Fasching CL, Reddel RR. 2000. Telomere maintenance by recombination in human cells. Nat Genet 26: 447-450.

Dynek JN, Smith S. 2004. Resolution of sister telomere association is required for progression through mitosis. Science 304: 97100.

Fouche N, Cesare AJ, Willcox S, Ozgur S, Compton SA, Griffith JD. 2006. The basic domain of TRF2 directs binding to DNA junctions irrespective of the presence of TTAGGG repeats. $J$ Biol Chem 281: 37486-37495.

Freibaum BD, Counter CM. 2006. hSnm1B is a novel telomereassociated protein. J Biol Chem 281: 15033-15036.

Galati A, Rossetti L, Pisano S, Chapman L, Rhodes D, Savino M, Cacchione S. 2006. The human telomeric protein TRF1 specifically recognizes nucleosomal binding sites and alters nucleosome structure. J Mol Biol 360: 377-385.

Gomez M, Wu J, Schreiber V, Dunlap J, Dantzer F, Wang Y, Liu Y. 2006. PARP1 is a TRF2-associated poly(ADP-ribose)polymerase and protects eroded telomeres. Mol Biol Cell 17: 1686-1696.
Gong Y, de Lange T. 2010. A Shld1-controlled POT1a provides support for repression of ATR signaling at telomeres through RPA exclusion. Mol Cell 40: 377-387.

Griffith J, Bianchi A, de Lange T. 1998. TRF1 promotes parallel pairing of telomeric tracts in vitro. J Mol Biol 278: 79-88.

Griffith JD, Comeau L, Rosenfield S, Stansel RM, Bianchi A, Moss H, de Lange T. 1999. Mammalian telomeres end in a large duplex loop. Cell 97: 503-514.

Guo X, Deng Y, Lin Y, Cosme-Blanco W, Chan S, He H, Yuan G, Brown EJ, Chang S. 2007. Dysfunctional telomeres activate an ATM-ATR-dependent DNA damage response to suppress tumorigenesis. EMBO J 26: 4709-4719.

Haber JE. 2004. Telomeres thrown for a loop. Mol Cell 16: 502 503.

Harper JW, Elledge SJ. 2007. The DNA damage response: Ten years after. Mol Cell 28: 739-745.

He H, Multani AS, Cosme-Blanco W, Tahara H, Ma J, Pathak S, Deng Y, Chang S. 2006. POT1b protects telomeres from endto-end chromosomal fusions and aberrant homologous recombination. EMBO J 25: 5180-5190.

Hefferin ML, Tomkinson AE. 2005. Mechanism of DNA doublestrand break repair by non-homologous end joining. DNA Repair 4: 639-648.

Her YR, Chung IK. 2009. Ubiquitin ligase RLIM modulates telomere length homeostasis through a proteolysis of TRF1. $J$ Biol Chem 284: 8557-8566.

Hockemeyer D, Daniels JP, Takai H, de Lange T. 2006. Recent expansion of the telomeric complex in rodents: Two distinct POT1 proteins protect mouse telomeres. Cell 126: 63-77.

Hockemeyer D, Palm W, Else T, Daniels JP, Takai KK, Ye JZ, Keegan CE, de Lange T, Hammer GD. 2007. Telomere protection by mammalian POT1 requires interaction with TPP1. Nat Struct Mol Biol 14: 754-761.

Hockemeyer D, Palm W, Wang RC, Couto SS, de Lange T. 2008. Engineered telomere degradation models dyskeratosis congenita. Genes Dev 22: 1773-1785.

Houghtaling BR, Cuttonaro L, Chang W, Smith S. 2004. A dynamic molecular link between the telomere length regulator TRF1 and the chromosome end protector TRF2. Curr Biol 14: $1621-1631$

Hsiao SJ, Smith S. 2008. Tankyrase function at telomeres, spindle poles, and beyond. Biochimie 90: 83-92.

Hsu HL, Gilley D, Galande SA, Hande MP, Allen B, Kim SH, Li GC, Campisi J, Kohwi-Shigematsu T, Chen DJ. 2000. Ku acts in a unique way at the mammalian telomere to prevent end joining. Genes Dev 14: 2807-2812.

Jackson SP, Bartek J. 2009. The DNA-damage response in human biology and disease. Nature 461: 1071-1078.

Kaminker PG, Kim SH, Taylor RD, Zebarjadian Y, Funk WD, Morin GB, Yaswen P, Campisi J. 2001. TANK2, a new TRF1associated PARP, causes rapid induction of cell death upon overexpression. J Biol Chem 276: 35891-35899.

Karlseder J, Broccoli D, Dai Y, Hardy S, de Lange T. 1999. p53and ATM-dependent apoptosis induced by telomeres lacking TRF2. Science 283: 1321-1325.

Kibe T, Osawa GA, Keegan CE, de Lange T. 2010. Telomere protection by TPP1 is mediated by POT1a and POT1b. Mol Cell Biol 30: 1059-1066.

Kim SH, Kaminker P, Campisi J. 1999. TIN2, a new regulator of telomere length in human cells. Nat Genet 23: 405-412.

Kim MK, Kang MR, Nam HW, Bae YS, Kim YS, Chung IK. 2008. Regulation of telomeric repeat binding factor 1 binding to telomeres by casein kinase 2-mediated phosphorylation. J Biol Chem 283: 14144-14152.

Konishi A, de Lange T. 2008. Cell cycle control of telomere protection and NHEJ revealed by a ts mutation in the DNA-binding domain of TRF2. Genes Dev 22: 1221-1230.

Lam YC, Akhter S, Gu P, Ye J, Poulet A, Giraud-Panis MJ, Bailey SM, Gilson E, Legerski RJ, Chang S. 2010. SNMIB/Apollo protects leading-strand telomeres against NHEJ-mediated repair. EMBO J 29: 2230-2241.

Lazzerini Denchi E, de Lange T. 2007. Protection of telomeres through independent control of ATM and ATR by TRF2 and 
POT1. Nature 448: 1068-1071.

Lee TH, Perrem K, Harper JW, Lu KP, Zhou XZ. 2006. The F-box protein FBX4 targets PIN2/TRF1 for ubiquitin-mediated degradation and regulates telomere maintenance. $J$ Biol Chem 281: 759-768.

Lee TH, Tun-Kyi A, Shi R, Lim J, Soohoo C, Finn G, Balastik M, Pastorino L, Wulf G, Zhou XZ, et al. 2009. Essential role of Pin1 in the regulation of TRF1 stability and telomere maintenance. Nat Cell Biol 11: 97-105.

Lei M, Podell ER, Cech TR. 2004. Structure of human POT1 bound to telomeric single-stranded DNA provides a model for chromosome end-protection. Nat Struct Mol Biol 11: 1223-1229.

Lejnine S, Makarov VL, Langmore JP. 1995. Conserved nucleoprotein structure at the ends of vertebrate and invertebrate chromosomes. Proc Natl Acad Sci 92: 2393-2397.

Lenain C, Bauwens S, Amiard S, Brunori M, Giraud-Panis MJ, Gilson E. 2006. The Apollo 5' exonuclease functions together with TRF2 to protect telomeres from DNA repair. Curr Biol 16: 1303-1310.

Li B, Oestreich S, de Lange T. 2000. Identification of human Rap1: Implications for telomere evolution. Cell 101: 471-483.

Lieber MR. 2010. The mechanism of double-strand DNA break repair by the nonhomologous DNA end-joining pathway. Annu Rev Biochem 79: 181-211.

Liu D, Safari A, O'Connor MS, Chan DW, Laegeler A, Qin J, Songyang Z. 2004. PTOP interacts with POT1 and regulates its localization to telomeres. Nat Cell Biol 6: 673-680.

Loayza D, de Lange T. 2003. POT1 as a terminal transducer of TRF1 telomere length control. Nature 424: 1013-1018.

Mahaney BL, Meek K, Lees-Miller SP. 2009. Repair of ionizing radiation-induced DNA double-strand breaks by non-homologous end-joining. Biochem J 417: 639-650.

Makarov VL, Lejnine S, Bedoyan J, Langmore JP. 1993. Nucleosomal organization of telomere-specific chromatin in rat. Cell 73: 775-787.

Martinez P, Thanasoula M, Munoz P, Liao C, Tejera A, McNees C, Flores JM, Fernandez-Capetillo O, Tarsounas M, Blasco MA. 2009. Increased telomere fragility and fusions resulting from TRF1 deficiency lead to degenerative pathologies and increased cancer in mice. Genes Dev 23: 2060-2075.

Martinez P, Thanasoula M, Carlos AR, Gomez-Lopez G, Tejera AM, Schoeftner S, Dominguez O, Pisano DG, Tarsounas M, Blasco MA. 2010. Mammalian Rap1 controls telomere function and gene expression through binding to telomeric and extratelomeric sites. Nat Cell Biol 12: 768-780.

Mimitou EP, Symington LS. 2009. Nucleases and helicases take center stage in homologous recombination. Trends Biochem Sci 34: $264-272$.

Moynahan ME, Jasin M. 2010. Mitotic homologous recombination maintains genomic stability and suppresses tumorigenesis. Nat Rev Mol Cell Biol 11: 196-207.

Muftuoglu M., Wong HK, Imam SZ, Wilson DM III, Bohr VA, Opresko PL. 2006. Telomere repeat binding factor 2 interacts with base excision repair proteins and stimulates DNA synthesis by DNA polymerase $\beta$. Cancer Res 66: 113-124.

Munoz-Jordan JL, Cross GA, de Lange T, Griffith JD. 2001. tloops at trypanosome telomeres. EMBO J 20: 579-588.

Murti KG, Prescott DM. 1999. Telomeres of polytene chromosomes in a ciliated protozoan terminate in duplex DNA loops. Proc Natl Acad Sci 96: 14436-14439.

Nikitina T, Woodcock CL. 2004. Closed chromatin loops at the ends of chromosomes. J Cell Biol 166: 161-165.

O'Connor MS, Safari A, Liu D, Qin J, Songyang Z. 2004. The human Rap1 protein complex and modulation of telomere length. J Biol Chem 279: 28585-28591.

O'Connor MS, Safari A, Xin H, Liu D, Z. Songyang Z. 2006. A critical role for TPP1 and TIN2 interaction in high-order telomeric complex assembly. Proc Natl Acad Sci 103: 11874 11879.

Opresko PL, Von Kobbe C, Laine JP, Harrigan J, Hickson ID, Bohr VA. 2002. Telomere binding protein TRF2 binds to and stimulates the Werner and Bloom syndrome helicases. J Biol Chem 277: 41110-41119.
Palm W, Hockemeyer D, Kibe T, de Lange T. 2009. Functional dissection of human and mouse POT1 proteins. Mol Cell Biol 29: 471-482.

Potts PR, Yu H. 2007. The SMC5/6 complex maintains telomere length in ALT cancer cells through SUMOylation of telomerebinding proteins. Nat Struct Mol Biol 14: 581-590.

Poulet A, Buisson R, Faivre-Moskalenko C, Koelblen M, Amiard S, Montel F, Cuesta-Lopez S, Bornet O, Guerlesquin F, Godet T, et al. 2009. TRF2 promotes, remodels and protects telomeric Holliday junctions. EMBO J 28: 641-651.

Rai R, Zheng H, He H, Luo Y, Multani A, Carpenter PB, Chang S. 2010. The function of classical and alternative non-homologous end-joining pathways in the fusion of dysfunctional telomeres. EMBO J 29: 2598-2610.

Reina-San-Martin B, Chen J, Nussenzweig A, Nussenzweig MC. 2007. Enhanced intra-switch region recombination during immunoglobulin class switch recombination in $53 \mathrm{BP}^{-/-} \mathrm{B}$ cells. Eur J Immunol 37: 235-239.

Rhodes D. 2005. The structural biology of telomeres. In Telomeres (ed. T de Lange et al.), pp. 317-344. Cold Spring Harbor Laboratory Press, Cold Spring Harbor, NY.

Saharia A, Stewart SA. 2009. FEN1 contributes to telomere stability in ALT-positive tumor cells. Oncogene 28: 1162-1167.

Saharia A, Guittat L, Crocker S, Lim A, Steffen M, Kulkarni S, Stewart SA. 2008. Flap endonuclease 1 contributes to telomere stability. Curr Biol 18: 496-500.

Sfeir A, Kosiyatrakul ST, Hockemeyer D, MacRae SL, Karlseder J, Schildkraut CL, de Lange T. 2009. Mammalian telomeres resemble fragile sites and require TRF1 for efficient replication. Cell 138: 90-103.

Sfeir A, Kabir S, van Overbeek M, Celli GB, de Lange T. 2010. Loss of Rap1 induces telomere recombination in the absence of NHEJ or a DNA damage signal. Science 327: 1657-1661.

Smith S, de Lange T. 2000. Tankyrase promotes telomere elongation in human cells. Curr Biol 10: 1299-1302.

Smith S, Giriat I, Schmitt A, de Lange T. 1998. Tankyrase, a poly(ADP-ribose) polymerase at human telomeres. Science 282: 1484-1487.

Smogorzewska A, Karlseder J, Holtgreve-Grez H, Jauch A, de Lange T. 2002. DNA ligase IV-dependent NHEJ of deprotected mammalian telomeres in $\mathrm{G}_{1}$ and $\mathrm{G}_{2}$. Curr Biol 12: 1635 .

Stansel RM, de Lange T, Griffith JD. 2001. T-loop assembly in vitro involves binding of TRF2 near the $3^{\prime}$ telomeric overhang. EMBO J 20: 5532-5540.

Storchova Z, Pellman D. 2004. From polyploidy to aneuploidy, genome instability and cancer. Nat Rev Mol Cell Biol 5: 45-54.

Svendsen JM, Smogorzewska A, Sowa ME, O'Connell BC, Gygi SP, Elledge SJ, Harper JW. 2009. Mammalian BTBD12/SLX4 assembles a Holliday junction resolvase and is required for DNA repair. Cell 138: 63-77.

Takai H, Smogorzewska A, de Lange T. 2003. DNA damage foci at dysfunctional telomeres. Curr Biol 13: 1549-1556.

Takai KK, Hooper S, Blackwood S, Gandhi R, de Lange T. 2010. In vivo stoichiometry of shelterin components. $J$ Biol Chem 285: $1457-1467$.

Teo H, Ghosh S, Luesch H, Ghosh A, Wong ET, Malik N, Orth A, de Jesus P, Perry AS, Oliver JD, et al. 2010. Telomere-independent Rap1 is an IKK adaptor and regulates NF- $\mathrm{BB}$-dependent gene expression. Nat Cell Biol 12: 758-767.

Tommerup H, Dousmanis A, de Lange T. 1994. Unusual chromatin in human telomeres. Mol Cell Biol 14: 5777-5785.

van Overbeek M, de Lange T. 2006. Apollo, an Artemis-related nuclease, interacts with TRF2 and protects human telomeres in S phase. Curr Biol 16: 1295-1302.

van Steensel B, Smogorzewska A, de Lange T. 1998. TRF2 protects human telomeres from end-to-end fusions. Cell 92: 401413.

Wang RC, Smogorzewska A, de Lange T. 2004. Homologous recombination generates T-loop-sized deletions at human telomeres. Cell 119: 355-368.

Wang F, Podell ER, Zaug AJ, Yang Y, Baciu P, Cech TR, Lei M. 2007. The POT1-TPP1 telomere complex is a telomerase processivity factor. Nature 445: 506-510. 
Wu P, de Lange T. 2008. No overt nucleosome eviction at deprotected telomeres. Mol Cell Biol 28: 5724-5735.

Wu L, Multani AS, He H, Cosme-Blanco W, Deng Y, Deng JM, Bachilo O, Pathak S, Tahara H, Bailey SM, et al. 2006. Pot1 deficiency initiates DNA damage checkpoint activation and aberrant homologous recombination at telomeres. Cell 126: 49-62.

Wu ZQ, Yang X, Weber G, Liu X. 2008. Plk1 phosphorylation of TRF1 is essential for its binding to telomeres. J Biol Chem 283: 25503-25513.

Wu P, van Overbeek M, Rooney S, de Lange T. 2010. Apollo contributes to $\mathrm{G}$ overhang maintenance and protects leading-end telomeres. Mol Cell 39: 606-617.

Ye JZ, Donigian JR, Van Overbeek M, Loayza D, Luo Y, Krutchinsky AN, Chait BT, de Lange T. 2004a. TIN2 binds TRF1 and TRF2 simultaneously and stabilizes the TRF2 complex on telomeres. J Biol Chem 279: 47264-47271.

Ye JZ, Hockemeyer D, Krutchinsky AN, Loayza D, Hooper SM,
Chait BT, de Lange T. 2004b. POT1-interacting protein PIP1: A telomere length regulator that recruits POT1 to the TIN2/ TRF1 complex. Genes Dev 18: 1649-1654.

Zeng S, Xiang T, Pandita TK, Gonzalez-Suarez I, Gonzalo S, Harris CC, Yang Q. 2009. Telomere recombination requires the MUS81 endonuclease. Nat Cell Biol 11: 616-623.

Zeng Z, Wang W, Yang Y, Chen Y, Yang X, Diehl JA, Liu X, Lei M. 2010. Structural basis of selective ubiquitination of TRF1 by SCFFbx4. Dev Cell 18: 214-225.

Zhu XD, Kuster B, Mann M, Petrini JH, de Lange T. 2000. Cellcycle-regulated association of RAD50/MRE11/NBS1 with TRF2 and human telomeres. Nat Genet 25: 347-352.

Zhu XD, Niedernhofer L, Kuster B, Mann M, Hoeijmakers JH, de Lange T. 2003. ERCC1/XPF removes the $3^{\prime}$ overhang from uncapped telomeres and represses formation of telomeric DNAcontaining double minute chromosomes. Mol Cell 12: 14891498. 


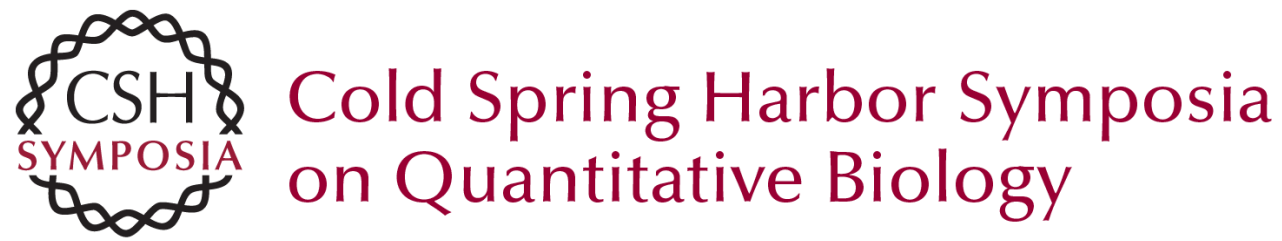

\section{How Shelterin Solves the Telomere End-Protection Problem}

T. de Lange

Cold Spring Harb Symp Quant Biol 2010 75: 167-177 originally published online January 5, 2011 Access the most recent version at doi:10.1101/sqb.2010.75.017

References This article cites 109 articles, 42 of which can be accessed free at: http://symposium.cshlp.org/content/75/167.full.html\#ref-list-1

License

Email Alerting Receive free email alerts when new articles cite this article - sign up in the box at the Service top right corner of the article or click here.

To subscribe to Cold Spring Harbor Symposia on Quantitative Biology go to:

http://symposium.cshlp.org/subscriptions 